\title{
The Concept of Innovative System of Enrollment in State Universities of Russia
}

\author{
Alexey Pykhtin
}

Maria Klevtsova

Oleg Ovchinkin

Inna Zeveleva

Southwest State University, 305040, st. 50 let Oktyabrya, 94, Kursk, Russia

Email: swsu.ee@gmail.com

\section{Doi:10.5901/mjss.2015.v6n5s1p149}

\section{Abstract}

The article offers new approach to distribution of the budgetary places between the higher education institutions subordinated to the Ministry of Education and Science of the Russian Federation, and carrying out competition among entrants allowing to allocate the most popular higher education institutions, to provide optimum conditions for entrants enrollment. The theoretical and methodological analysis of the research of the experience of entrants reception in the countries with various type of economy has been carried out. The offered system of reception of entrants will allow to coordinate the market of educational services and labor market and will promote the emergence of synergetic effect from their interaction. Introduction of practice of allocation of the budgetary places on the basis of data on the entrants who presented originals of the aforecited certificates and documents on education to educational institution will finally allow to resolve an issue of what higher education institution is preferable more to entrants who will raise a rating of higher education institution, presenting to it the certificates. The article reveals the innovative system of reception of entrants offered by authors in higher education institutions in the Russian Federation. The offered system has the universal, unified character and can be used in various countries.

Keywords: higher education institution; entrant; competition

\section{Introduction}

Nowadays there is a certain system of interrelations in educational system in the Russian Federation, regarding the budgetary financing, connected with reception of entrants in higher education institutions. Primary link is the state, being in essence the customer, the second link is higher education institution (acts as the producer), the third link is the student (as the consumer of the first level) and the employer (as the consumer of the second level). Thus, in the existing system of reception of entrants higher education institution which at the same time acts also as the producer has a priority at a choice of the directions of financing, i.e. at a choice of the directions of training of entrants on the budgetary basis. Similar approach is close to a command management system, in which questions "what to make?" and "how to make?" are decided centrally, and a question "for whom to make?" isn't so actual. The similar algorithm of reception is specific also for the budgetary higher education institutions of Great Britain where reception of entrants is carried out on the basis of estimates according to the certificate in three subjects which are defined independently by higher education institution and faculty.

The innovative system of reception of entrants we offer will allow to redirect this process to the market principles where potential students as consumers and employers will have "rights of the first voice" as the directions of the budgetary financing are chosen in fact by the student. Thus, already at the first stage of introduction of the offered system the question "for whom?" is updated also there will be a partial reorientation to market approaches. At the second stage of introduction, when forming a rating of higher education institutions, there will be an orientation to consumers of the second level - employers.

The advantage of the offered system of reception of entrants is transition to target, "pointed" financing that excludes dispersion of budgetary funds and emergence of the problems similar to problems of France in the field of education.

In France the lack of budgetary funds and almost total absence of private financing conduct to outflow of highly skilled administrators, teachers and scientists from university system, negatively influence quality, training and the 
research and development level, reduce appeal of this type of preparation at youth, especially in the sphere of the precise sciences and on engineering specialties.

The process of transfer of students to universities in many respects has formal character, without serious binding to requirements of labor market. Such approach conducts to the fact that 4 of 10 French students give up study without obtaining any diploma (in Japan - 1 of 10), and many of them are compelled to change the chosen specialization and to pass into other educational institutions, as a rule, of lower level. The statistics shows that over $10 \%$ of graduates of universities can't find work within three years, and every third one is compelled to seek employment not in their field.

\section{Materials and Methods}

Works of many authors are dedicated to the theoretical and methodological analysis of features of reception of entrants in higher education institutions. In various countries such researchers as Boaz Shulruf, Rolf Turner, John Hattie (2009), Min Zhu (2014), James Friedrich, Gale Lucas, Emily Hodell, (2005) were engaged in studying problems and detection of specific characteristics of reception of entrants, in particular, advisability of use of entrance tests was investigated - in China (Guangliang Yang, 2014) and in the USA (Zwick R., 2010). Authors also considered practical experience of use of system of quoting at reception in universities of Germany (Sebastian Braun, Nadja Dwenger, Dorothea Kübler, Alexander Westkamp, 2014). The essential contribution to research of policy of receipt to higher education institutions not only in developed, but also in developing countries was brought by such scientists as (Sudhanshu Handa, Peter-John Gordon, 1999).

The main materials when carrying out research were the results of fundamental and applied development in the field of realization of procedure of reception of entrants in higher educational institutions, normative legal acts, articles served in specialized magazines and scientific publications, materials of the international conferences.

As a methodological basis we used the dialectic method providing studying of the phenomena in the conditions of dynamic development, interrelation of separate elements of system and allocation of the leading elements of clusters as difficult social and economic systems. For the solution of objectives we used theoretical and empirical methods, in particular, methods of the system and monographic analysis. In the course of research we used general scientific receptions of the analysis and synthesis, comparative methods.

\section{Results and Discussion}

In 2009 in Russia transition to the unified state examination (USE) as to the main way of control of knowledge for graduates of schools and to the main selection criterion for training in higher educational institutions came to the end. Students of the 11th grades are obliged to choose the list of the handed-over subjects of Unified State Examinations till the 1st of March of the year in which they finish training. This information is gathered by educational authorities and accumulated in a uniform information database. On the basis of these data the necessary amount of examination materials in each subject is prepared. At the end of May - the first half of June graduates of schools and other persons pass examinations in the form of Unified State Examination in the subjects chosen by them and their results are brought in a federal database.

Since 2012 the Ministry of Education and Science of the Russian Federation made the decision on allocation of the budgetary places to higher education institutions not on the integrated groups of the directions of preparation and specialties, but on the certain directions of training of bachelors and masters and specialties according to federal state educational standards [1]. According to the Ministry of Education and Science of the Russian Federation carried out distribution of places in the certain directions, forms of education and education levels for carrying out competition among higher education institutions on establishment of target figures of reception in 2012 at the expense of means of the federal budget. So, for example, for the direction of training of bachelors 231000.62 "Program engineering" there were allocated 1585 budgetary places on full-time tuition. Besides, since 2012 the Ministry of Education and Science of the Russian Federation passed to the scheme of "per capita" financing of higher education institutions. That is if the higher education institution receives $\mathrm{N}$ budgetary places in some direction of preparation (specialty), they annually state subsidy to this higher education institution at a rate of $\mathrm{N}^{*} \mathrm{~K}$ of rubles, where $\mathrm{K}$ is the standard of costs of unit of the state service for reception given for the first course in the current year which differs for different specialties, form of education and education level.

We will note that the list of subjects which need to be handed over to enter this or that specialty (the direction of preparation), is also approved by the order of the Ministry of Education and Science of the Russian Federation. On the one hand any higher education institution in Russia can independently choose subjects within this list, but on the other 
hand there are not a lot of alternative options. One of 4 subjects is a profile one and it has to be included by a higher education institution in the final list of examinations, Russian is also obligatory. Higher education institution is provided 3 options on its choice: to leave the 1st of the remained subjects, to leave the 2 nd subject or to include both. As the statistics of reception campaigns of 2009-2012 shows that the same entrance tests are established on the same directions of training of bachelors and masters at the majority of the Russian universities. For example, in the order of the Ministry of Education and Science of the Russian Federation to enter the direction of training of bachelors 270800.62 "Construction" the following subjects are specified: mathematics (main), physics, chemistry, Russian. The majority of the higher education institutions in Russia realizing an educational program for this direction defined the following combination of entrance tests: mathematics, physics, Russian. There are a lot of such examples. This synchronism in actions of educational institutions is connected with the fact that when determining lists of entrance tests higher education institutions are guided by statistics on a choice of subjects of Unified State Examinations by entrants. So annually much more entrants hand over physics (for example, 208875 people in 2013), than chemistry (93 802 persons in 2013) [2].

Since 2012 the federal information system of ensuring of Unified State Examination and reception to average special educational institutions and higher education institutions (FIS) is put into operation for strengthening of control measures over observance of normative documents in the field of enrollment of students, for ensuring the maximum openness of procedures of reception in relation to entrants. FIS is a new stage in development of a federal database of evidence of Unified State Examination (FDS). In FIS all data on entrants of each Russian higher education institution are brought with the indication of the specialties and the directions chosen by them for receipt, the privileges gained on Unified State Examination and entrance tests points, etc.

Thus, now before transfer to the 1st course in higher education institutions and average special educational institution the Ministry of Education and Science of the Russian Federation possesses the following information:

1) the full list of all future entrants with the indication of their surname, name, middle name, date of birth and the passport data which confirmed desire to pass the Unified State Examination in the current year;

2) information about the subjects of Unified State Examination chosen by each entrant;

3) quantity of the budgetary places on each direction of preparation or specialty;

4) results of Unified State Examination of each entrant (after the end of procedure of carrying out Unified State Examination for all Russia).

Let us assume that the following two conditions will be satisfied: first, at the stage of delivery of demands for Unified State Examination all school students will also bring in a federal database the list of specialties and the directions of preparation which they are going to enter (with the indication of form of education - full-time, part-time and extramural), and information on having privileges and the rights for receipt without entrance tests, secondly, in all higher education institutions of Russia identical entrance tests will be declared on the identical directions of preparation and specialties. In addition we can ask future entrants to provide information about higher educational institutions they are planning to enter. It will allow to make rather objective rating of educational institutions of Russia on preferences of entrants.

If these two assumptions are realized (that is not of great complexity with introduction of FIS), it will be possible to realize new algorithm of competitive selection and transfer to higher education institutions of Russia. Its essence is as follows. For each separate specialty or the direction of preparation on each separate form of education the list of all entrants in Russia who specified it at registration for Unified State Examination is to be built. For each entrant from this list the score by results of Unified State Examination is calculated, on condition the examinations are passed more than for the "two threshold" established annually for a subject. The persons who passed the Unified State Examination for unsatisfactory point are excluded from such list. The list is ranged on decrease of a score taking into account the persons having the right for out-of-competition receipt (for example, orphan children) who will go at the top of the list.

For example, we suppose, that in 2015 the Unified State Examination in informatics will be passed by 60000 people (in 201358851 persons chose this subject). Let's say that 20\% of them, i.e. 12000 people, would like to enter the "Program Engineering" direction. We will assume that 10000 of them successfully passed all 3 Unified State Examination (in mathematics, informatics and Russian). In this case we would receive the rating list from 12000 entrants applying for 1500 budgetary places, i.e. the All-Russian competition will make 8 people for a place.

The persons heading such integrated rating lists are the most prepared entrants in Russia and have to be recommended for transfer for the places financed by funds of the federal budget for the corresponding specialty and form of education. At construction similar rating lists education authorities in Russia can define various threshold points for the purpose of management of possible number of off-budget students in the country.

By the results of such All-Russian competition each entrant can be granted the certificate confirming the fact that the entrant deserved the right to be trained at the expense of means of the federal budget. In that case instead of carrying out open public competition from higher education institutions the budgetary places and respectively financing to 
educational institutions can be distinguished on the basis of data on the entrants who presented originals of the above certificates and documents on education to an educational institution.

Introduction of such practice will finally allow to resolve an issue of what higher education institution is preferable more to entrants who will raise a rating of higher education institution, presenting the certificates to it.

In case the entrant is recommended for transfer in several directions of preparation or specialties, it is possible to use system of the priorities expressing interest of the entrant in enyering each of the directions chosen by it. The higher the priority is the more a specified specialty corresponds to the preferences of the entrant. Respectively, the entrant is considered recommended for transfer only for 1 specialty with the greatest priority, and is excluded from the other rating lists with smaller priorities. Such exception of the lists leads to recalculation of all competitive situation therefore for correct formation of total rating lists it is necessary to use special algorithms, for example [3].

It is natural that there is a number of higher education institutions which won't be limited at reception only for the results of Unified State Examination and will carry out additional entrance tests of a profile, creative or professional orientation. Such right can be granted to a certain list of higher education institutions (as it is organized now), having allowed to hold additional competition among the entrants having certificates by results of the entrance tests conducted by educational institution independently. It is also possible to allow higher education institutions to make additional selection, for example, on the basis of existence of places in the hostel for the non-resident entrants.

We will note that the entrant can grant the right to be transferred from the university he entered on the basis of the certificate to any other if he or she successfully passes sessions, but won't be satisfied with the quality of educational or other services of initially chosen educational institution.

In this approach the Ministry of Education and Science of the Russian Federation will be also able to control number of off-budget students. Knowing a deal over all the country, it is possible to establish for each direction of preparation or specialty value of "threshold" point in each subject so that the number of potential students corresponded to needs of Russia for specialists with education of the corresponding profile.

\section{Conclusion}

The approach developed by us will lead to emergence of the synergetic effect which is expressed in several aspects:

a) higher education institutions will seek to increase prestigiousness of training and quality of education without additional financial investments;

b) employers will be sure at the qualification of the graduate;

c) the system of effective contracts is possible (higher education institution as an employer); and entering into contracts that higher education institution provides graduates first of all to this enterprise;

d) increase in demand for young specialists, removal of social tension in labor market;

e) the special attention will be paid to preliminary career guidance of potential students. It will allow them to choose the specialties demanded in labor market more motivatedly, to pull together system of training with requirements of economy, to lower unemployment rate, costs of retraining of certified specialists.

However, besides the advantages, there can be some "bottlenecks", the decision on which has to have anticipatory character.

First, there can inevitably occur a certain rivalry between universities and, as a result, their "high-quality stratification" at the expense of a factor of more effective management and distinction of financial resources. As a result many regional higher education institutions will lose the ratings, and the level of prestige of training in such higher education institutions will be the lowest that will lead to additional social problems in these regions.

Secondly, at a close binding of the directions of preparation at universities for requirements of labor market the emphasis can be placed only on modern technologies. These directions are not always popular among entrants in connection with complexity of training. If entrants have rights of the first voice, other "failure" towards humanitarian specialties is possible, because labor market is saturated with them, but training is rather simple.

And, thirdly, at application of an external assessment of universities for the purpose of the analysis of achievements and shortcomings, it will lead to occurrence of potential threat of reorganization of higher education institutions, their merges and closing.

\section{Acknowledgements}

The work is performed within a grant of the President of the Russian Federation by MK-5226.2015.8. 


\section{References}

"The announcement of carrying out open public competition on establishment of target figures of a reception of citizens in the directions of preparation (specialties) for training at the expense of means of the federal budget for 2012" [Online]. - M.: 2012. Available: http://minobrnauki.rf/novosti/2066. Title from the screen.

"Unified State Examination statistics" [Online]. - M.; 2015. Available: http://www.ege.edu.ru/ru/main/satistics-ege/. - Title from the screen.

Pykhtin, A.I. (2007) "Formalization of a problem of competitive selection and transfer", News of Southwest state university. 4. 112.

To the Minister of Foreign Affairs of the Russian Federation about the system of reception existing in other countries in the highest professional educational institutions http://www.smolin.ru/electorate/letters_smolin/2010-02-02.htm

Tchjaomin Chen (2010) "Reforming of an education system in China", the Humanitarian vector. Series: Pedagogics, psychology. 1. 6169.

Min Zhu (2014) "College admissions in China: A mechanism design perspective", China Economic Review Volume 30. 618-631. http://dx.doi.org/10.1016/j.chieco.2013.08.006

Sebastian Braun, Nadja Dwenger, Dorothea Kübler, Alexander Westkamp (2014) Implementing quotas in university admissions: An experimental analysis, Games and Economic Behavior. 85. 232-251. http://dx.doi.org/10.1016/j.geb.2014.02.004

Guangliang Yang (2014) "Are all admission sub-tests created equal? — Evidence from a National Key University in China", China Economic Review. 30. 600-617. http://dx.doi.org/10.1016/j.chieco.2013.12.002

Stijn Broecke (2012) "University selectivity and earnings: Evidence from UK data on applications and admissions to university", Economics of Education Review. V31, 31- 3. 96-107. http://dx.doi.org/10.1016/j.econedurev.2012.02.005

James Friedrich, Gale Lucas, Emily Hodell (2005) "Proportional reasoning, framing effects, and affirmative action: Is six of one really half a dozen of another in university admissions? " Organizational Behavior and Human Decision Processes. 98- 2. 195-215. http://dx.doi.org/10.1016/j.obhdp.2005.06.002

Sudhanshu Handa, Peter-John Gordon (1999) "University admissions policy in a developing country: evidence from the University of the West Indies", Economics of Education Review. 18- 2. 279-289. http://dx.doi.org/10.1016/S0272-7757(98)00039-9

Zwick R. (2010) "Admissions Testing ", International Encyclopedia of Education (Third Edition) , 7-14.

Boaz Shulruf, , Rolf Turner, John Hattie (2009) "A Dual admission model for equity in higher education: a multi-cohort longitudinal study", Procedia - Social and Behavioral Sciences Volume 1, Issue 1. 2416-2420. http://dx.doi.org/10.1016/j.sbspro.2009.01.424 